Note

\section{State of Water in Maillard-reacted Ovalbumin as Studied by Broad-line Pulsed NMR}

\author{
Yasuko Kato, Ei-ichiro Suzuki, ${ }^{*}$ \\ Nobuya Nagashima, ${ }^{*}$ Kenji Watanabe** \\ and Ryo NaKamura** \\ Women's College of Tokaigakuen, \\ Tenpaku-ku, Nagoya 468, Japan \\ *Central Research Laboratories, \\ Ajinomoto Co., Inc., Suzuki-cho, \\ Kawasaki-ku, Kawasaki 210, Japan \\ **Faculty of Agriculture, Nagoya University, \\ Chikusa-ku, Nagoyo 464, Japan
}

Received March 28, 1983

It has been known that carbohydrate moieties in glycoprotein $^{1,2)}$ and lactosylated enzyme ${ }^{3)}$ contribute to the stabilization of their protein moieties against heat and other denaturing conditions. The conformational stability of ovalbumin reacted with glucose in the Maillard reaction has also been demonstrated in our previous studies. ${ }^{4 \sim 6}$ ) Such a stabilization of protein-sugar conjugates has been reported to be associated with noncovalent interaction and cross-linking between carbohydrate and protein, and the degree of hydration. ${ }^{1,3,6)}$ This study describes the state of water in Maillard-reacted ovalbumin as studied by broadline pulsed NMR in order to get information on the conformational characteristics from the aspect of hydration.

Freeze-dried ovalbumin containing D-glucose corresponding to $30 \%$ of the dry weight was stored for 4 days at $50{ }^{\circ} \mathrm{C}$ and $65 \%$ relative humidity, and the monomer type of the Maillard-reacted complex (mOVG) was separated from the polymer one by Sephadex G-150 column chromatography after removing the unreacted ovalbumin by mild heat-treatment, dialyzed and freeze-dried as described previously. ${ }^{4}$ 7) The mOVG which showed only one band on polyacrylamide gel electrophoresis, was estimated to be partially denatured from circular dichroism (CD) spectra (denaturation ratio calculated from $\alpha$ helix content: $18 \%$ ) even though $62 \%$ of $\varepsilon$-amino groups were blocked, and could be recognized to be a product in the initial stage of the Maillard reaction from the quantity of lysine present as fructoselysine (6.2 to 20 residues of total lysine). ${ }^{6)}$

Measurements of unfrozen water (UFW) content and spin-spin relaxation time $T_{2}$ as a function of temperature were carried out using Bruker minispec p20 broad-line pulsed NMR spectrometer $(20 \mathrm{MHz}$ for observation of $\left.{ }^{1} \mathrm{H}\right)$ equipped with a minicomputer system (HP 1000). ${ }^{8)} \mathrm{A}$ sample in a $7 \mathrm{~mm}$ OD glass tube was cooled or warmed at the rate of about $3^{\circ} \mathrm{C} / \mathrm{min}$ using nitrogen gas and liquid nitrogen. The sample temperature was measured with a chromel-constantan thermocouple inserted in the sample tube. The UFW content was determined by extrapolating the liquid portion of the free induction decay curve after $90^{\circ}$ pulse and $T_{2}$ was calculated from its slope. These procedures were done at every pulse with the minicomputer and the results were plotted as a function of temperature on a semi-logarithmic graph by graphic plotter. The samples of $\mathrm{OV}$ and $\mathrm{mOVG}$ were dissolved in distilled water at $40 \%$ concentration of freeze-dried materials. Concentrations with respect to protein solutions were $36 \%$ for the former and $26 \%$ for the latter.

UFW contents as a function of temperature in aqueous solutions of OV and mOVG in the freezing and thawing processes are shown in Fig. 1a and b. UFW contents with the thawing process at $-30^{\circ} \mathrm{C}$ per gram of dry $\mathrm{OV}$ and mOVG were $0.318 \mathrm{~g}$ and $0.308 \mathrm{~g}$, respectively. One gram of mOVG contained $0.85 \mathrm{~g}$ of protein and $0.15 \mathrm{~g}$ of hexose, of which the main carbohydrates were glucose and fructose. It has been shown that both free glucose ${ }^{8)}$ and fructose ${ }^{9)}$ could hold $0.2 \mathrm{~g}$ of bound water per gram of samples with a broad-line pulsed NMR spectrometer. And it has also been pointed out that the denatured form of protein was more heavily hydrated than the native conformation, and native ovalbumin held $0.323 \mathrm{~g}$ of bound water against $0.332 \mathrm{~g}$ for the denatured one. ${ }^{10)}$ Judging from these

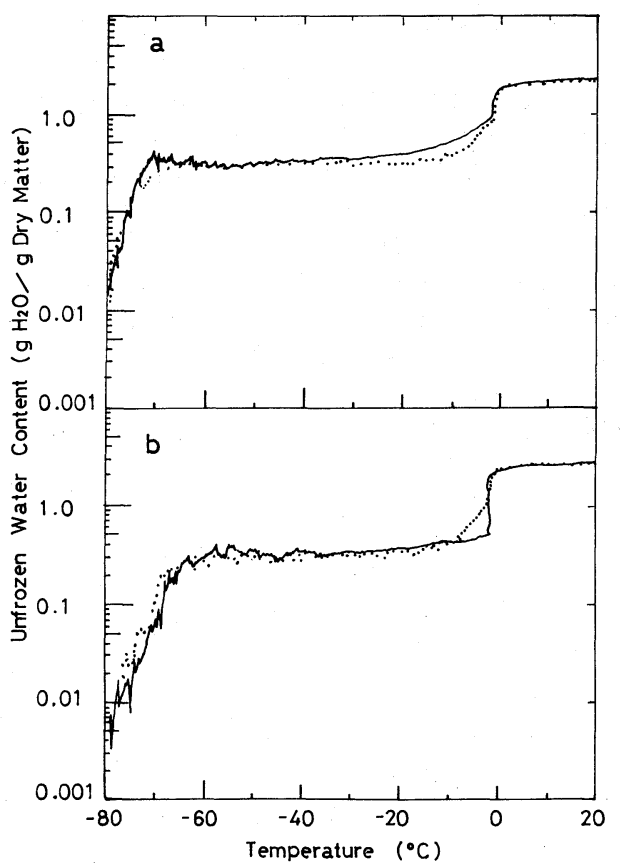

FIG. 1. UFW Contents as a Function of Temperature in Aqueous Solutions of OV (a) and mOVG (b) in the Freezing (-) and Thawing (-----) Processes. 


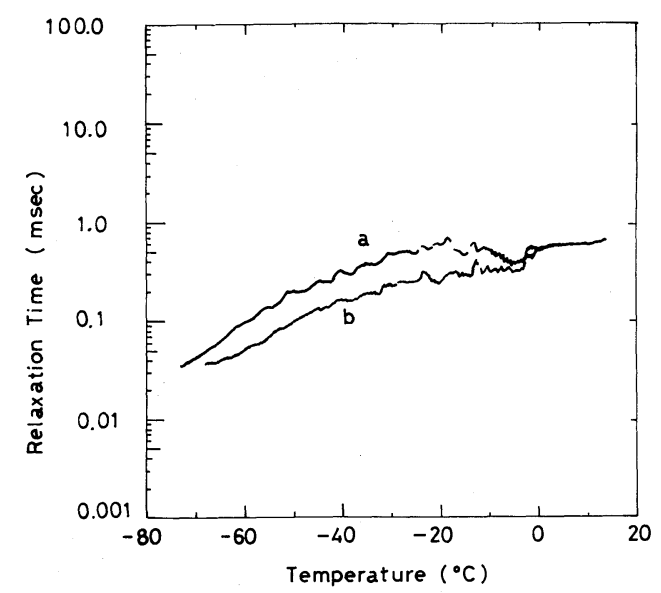

FIG. 2. Spin-Spin Relaxation Time $T_{2}$ as a Function of Temperature of UFW in Aqueous Solutions of OV (a) and mOVG (b) with the Thawing Process.

reported values, the attachment of hexose to OV might not result in the increase of bound water in the carbohydrateprotein complex, although $\mathrm{mOVG}$ in a slightly denatured form might hold additional bound water. This estimation agreed with the result that the UFW content of mOVG was slightly less than that of OV as described above. Thus, the difference of hydration between OV and mOVG can not be explained by the UFW content.

The freezing curves in Fig. 1 show the difference between $\mathrm{OV}$ and $\mathrm{mOVG}$ in weakly bound water from 0 to $-20^{\circ} \mathrm{C}$ (this was regarded as weakly bound water by Nagashima and Suzuki ${ }^{11}$ ), for the mOVG curve suddenly dropped at $0^{\circ} \mathrm{C}$ (Fig. 1b), but that of $\mathrm{OV}$ dropped gradually from 0 to $-20^{\circ} \mathrm{C}$ (Fig. 1a). These results indicate that $\mathrm{OV}$ has some weakly bound water, whereas mOVG has almost none.

Spin-spin relaxation time $T_{2}$ as a function of temperature of UFW in aqueous solutions of $\mathrm{OV}$ and $\mathrm{mOVG}$ with the thawing process is shown in Fig. 2. The $T_{2}$ values of $\mathrm{OV}$ and $\mathrm{mOVG}$ at $-30^{\circ} \mathrm{C}$ were 0.49 and $0.23 \mathrm{msec}$, respectively. The molecular mobility of unfrozen water in
mOVG was found to be depressed more than in OV. This would depend on the facts that mOVG had a different conformation from OV to hold tightly bound water, and the possibility that bound water in mOVG might be interposed between protein and bound carbohydrate.

Not only tightly bound water but also weakly bound water has been reported to affect protein thermodenaturation. ${ }^{12,13)}$ However, more studies are needed to clarify the contribution of bound water, especially that tightly bound water expressed by $T_{2}$, to the conformational stability of mOVG.

\section{REFERENCES}

1) J. J. Marshall and M. L. Rabinowitz, Arch. Biochem. Biophys., 167, 777 (1975).

2) S. Hayashida and H. Yoshioka, Agric. Biol. Chem., 44, 481 (1980).

3) J. W. Marsh, J. Denis and J. C. Wriston, Jr., J. Biol. Chem., 252, 7678 (1977).

4) Y. Kato, K. Watanabe and Y. Sato, J. Food Sci., 46, 1835 (1981).

5) Y. Kato, K. Watanabe and Y. Sato, J. Agric. Food Chem., 29, 540 (1981).

6) Y. Kato, K. Watanabe and Y. Sato, Agric. Biol. Chem., 47, 1925 (1983).

7) K. Watanabe, Y. Kato and Y. Sato, J. Food Process. Preserv., 3, 263 (1980).

8) E. Suzuki and N. Nagashima, Chem. Lett., 181 (1981).

9) H. K. Leung and M. P. Steinberg, J. Food Sci., 44, 1212 (1979).

10) I. D. Kuntz and W. Kauzmann, Ad. Protein Chem., 28, 239 (1974).

11) N. Nagashima and E. Suzuki, "Water Activity," ed. by L. B. Rockland and G. F. Steward, Academic Press, New York, 1981, pp. $247 \sim 264$.

12) M. Rügg, V. Moor and B. Banc., Biochim. Biophys. Acta, 400, 334 (1975).

13) Y. Fujita and Y. Noda, Bull. Chem. Soc. Jpn., 51, 1567 (1978). 